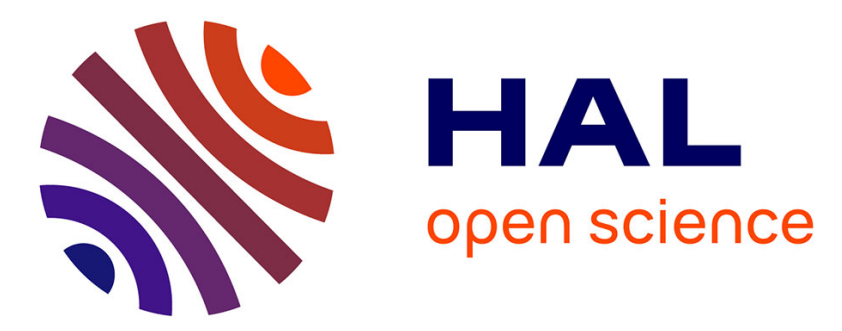

\title{
Characterization of chitosan/montmorillonite bionanocomposites by inverse gas chromatography
}

\author{
S. Bensalem, B. Hamdi, Sylvie del Confetto, M. Iguer-Ouada, Alain
}

Chamayou, H. Balard, Rachel Calvet

\section{- To cite this version:}

S. Bensalem, B. Hamdi, Sylvie del Confetto, M. Iguer-Ouada, Alain Chamayou, et al.. Characterization of chitosan/montmorillonite bionanocomposites by inverse gas chromatography. Colloids and Surfaces A: Physicochemical and Engineering Aspects, 2017, 516, p. 336-344. 10.1016/j.colsurfa.2016.12.051 . hal-01619253

\section{HAL Id: hal-01619253 \\ https://hal.science/hal-01619253}

Submitted on 7 Nov 2018

HAL is a multi-disciplinary open access archive for the deposit and dissemination of scientific research documents, whether they are published or not. The documents may come from teaching and research institutions in France or abroad, or from public or private research centers.
L'archive ouverte pluridisciplinaire HAL, est destinée au dépôt et à la diffusion de documents scientifiques de niveau recherche, publiés ou non, émanant des établissements d'enseignement et de recherche français ou étrangers, des laboratoires publics ou privés. 


\title{
Characterization of chitosan/montmorillonite bionanocomposites by inverse gas chromatography
}

\author{
S. Bensalem ${ }^{\mathrm{a}, *}$, B. Hamdi ${ }^{\mathrm{b}, \mathrm{c}}$, S. Del Confetto ${ }^{\mathrm{d}}$, M. Iguer-Ouada ${ }^{\mathrm{e}}$, A. Chamayou $^{\mathrm{d}}$, H. Balard ${ }^{\mathrm{f}}$, \\ R. Calvet ${ }^{\mathrm{d}}$
}

a Univ. Ouargla, Faculté des Sciences de la Nature et de la Vie, Département des Sciences Biologiques, Ouargla, 30000, Algeria

b Laboratoire d'Etude Physico-Chimique des Matériaux et Application à l'Environnement, Faculté de Chimie, USTHB, BP 32 El Alia, Bab Ezzouar, 16111, Alger, Algeria

' ENSSMAL, BP 19 Bois des Cars, Dely Ibrahim, 16320, Alger, Algeria

'Université de Toulouse, Mines Albi, CNRS UMR 5302, Centre RAPSODEE, Campus Jarlard, F-81013, Albi Cedex 09, France

e Laboratoire Ecosystème Marin et l'Aquacole, Faculté des Sciences de la Nature et de la Vie, Université Abderrahmane-Mira, 06000, Bejaia, Algeria

${ }_{\mathrm{f}}^{\mathrm{f}}$ Adscientis, 1 Rue Kastler, 68310, Wittelsheim, France

\section{H I G H L I G H T S}

- Chitosan/montmorillonite bionanocomposites, prepared in liquid phase are characterized.

- XPS patterns show the chitosan intercalation in the montmorillonite layered.

- Surface parameters are determined by inverse gas chromatography.

- Surface parameters are sensitive to chitosan intercalation in montmorillonite structure.

- The increase in the chitosan mass ratio leads to the progressive disappearance of high energy sites.

\section{Keywords:}

Chitosan

Montmorillonite

Bionanocomposite

Inverse gas chromatography

XPS

Surface heterogeneity
G R A P H I C A L A B S T R A C T
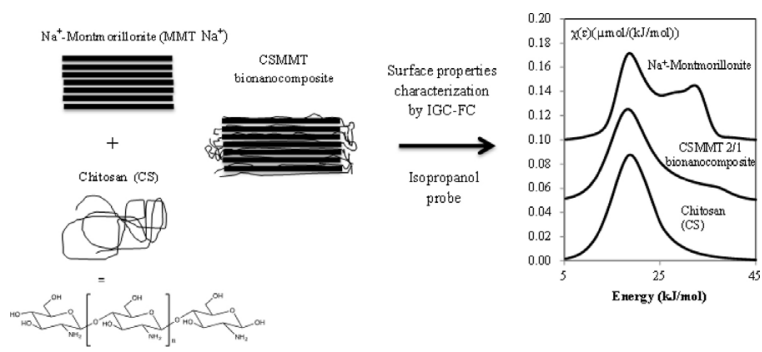

The distribution function obtained by inverse gas chromatography at finite concentration on the bionanocomposite shows the disappearance of the shoulders at high energy after intercalation/adsorption of chitosan in montmorillonite galleries.

\section{A B S T R A C T}

Montmorillonite was modified with different amounts of chitosan to obtain chitosan/montmorillonite bionanocomposites (CSMMT). The structural and surface characteristics of the raw materials and bionanocomposites were analyzed. XPS results showed that the obtained bionanocomposites had MMT-rich surfaces with chitosan essentially intercalated in the host clay galleries. IGC at infinite dilution confirmed that the increase of CS mass ratio in the bionanocomposites significantly affected the surface properties. IGC at finite concentration revealed a clear evolution in the surface heterogeneity in chitosan/montmorillonite bionanocomposites by the progressive disappearance of shoulders of high energy with the increase of CS mass ratio in MMT.

\footnotetext{
* Corresponding author.

E-mail address: soufiane.bensalem@yahoo.fr (S. Bensalem).
}

\section{Introduction}

Bionanocomposites based on biopolymers and clays have received considerable attention over the last decade due to their 
new structure and functional properties. They are formed by the combination of natural polymers and clays and show at least one dimension on the nanometric scale [1]. Thus, the resulting materials are characterized by properties inherent to both types of components [2]. One of the most extensively-used filler materials in bionanocomposite is the smectite class of aluminum silicate clays, of which the most common representative is montmorillonite (MMT).

Montmorillonite (MMT) is a 2:1 type aluminosilicate. Its crystalline structure presents an alumina octahedral between two tetrahedral layers of silica [3]. The layers of MMT are negative in nature and this charge can be neutralized by a counter cation (generally the $\mathrm{Na}^{+}$cation), which is situated in the gap between the layers. This cation can be modified by cationic exchange reactions with other cations such as Nickel, Cobalt and Zinc [4], cationic surfactants [5], salts of fatty acids [6] and polymers [7].

Biopolymers commonly used in bionanocomposites are proteins, phospholipids, biopolyesters such as polylactic acid, nucleic acids, and polysaccharides such as starch, cellulose, xanthan gum or chitosan (CS). CS is the second most abundant natural polysaccharide in the world after cellulose.

CS is a linear cationic poly- $\beta$ - $(1,4)-2$-amino-2-deoxyglucopyranose with a variable degree of N-deacetylation. It is mainly extracted from shrimp bio-waste [8]. Under slightly acidic conditions, most of the amino groups of CS are protonated and the resulting CS contains multiple cationic charges. CS is considered one of the most valuable polymers for environmental, biomedical and pharmaceutical applications due to its properties of biodegradability, biocompatibility, antimicrobial effects, good film formation, and high positive charge [9,10]. Furthermore, the polyelectrolyte positive charges of CS are able to intercalate MMT and other smectites by ion-exchange reactions [11,12], the resulting bionanocomposites showing interesting structural and functional properties [2].Since chitosan-montmorillonite bionanocomposites exhibit good functional and mechanical properties, they are widely used as active phases in sensors for potentiometric determination [13], for the removal of heavy metals such as Cobalt [14], for dyes removal [15] and as antimicrobial materials [16]. It is, therefore, of fundamental and technological importance to determine their surface chemical composition and surface energy because these physicochemical properties are directly correlated with the strength of the CS-MMT clay interaction.

The surface chemical composition can be determined by an appropriate surface analytical technique such as X-ray photoelectron spectroscopy (XPS), whereas the surface energy of powders is best assessed by inverse gas chromatography (IGC).

Inverse gas chromatography (IGC) is a commonly-used method for physicochemical characterization of the surface properties of divided solids and in the study of adsorption phenomena. IGC has already been implemented in the analysis of clays, such as attapulgite [17], bentonite [18], smectite [19], of polymers like chitin [20] and of various nanocomposites, such as montmorillonite/PVC [21], montmorillonite/polypyrole [22] and rectorite/thermoplastic polyurethane [23].

In this study, various bionanocomposites based on CS and MMT were prepared in a liquid phase. The influence of CS mass ratio on the bionanocomposites powders was examined by different techniques and compared to those of the raw materials, the pure MMT $\mathrm{Na}^{+}$and CS. The surface composition of the bionanocomposites was determined by XPS. IGC at finite and infinite dilution was implemented to determinate surface free energy, acid-base properties and to examine surface energetic heterogeneity of raw materials and bionanocomposites.

\section{Theory of inverse gas chromatography (IGC)}

\subsection{Inverse gas chromatography at infinite dilution (IGC-ID)}

IGC is an extension of conventional analytical gas chromatography. It provides information about surface properties, regardless of the nature of the solid examined in the chromatographic column.

IGC can be carried out in two ways: at infinite dilution (IGC-ID) and at finite concentration (IGC-FC). IGC-ID consists in the injection of negligible amounts (vapor) of well-identified molecules, called probes, into a column filled with the solid that is being tested. At infinite dilution (Henry's domain), the interactions between the probe and the solid material are calculated from the retention times, and the surface properties of the solid are determined.

The dispersive component of surface energy, $\gamma_{d}^{s}$, is calculated when $n$-alkanes are injected as probes. The assumption is that only dispersive interactions exist between $n$ - alkanes and the solid. Experimentally, the $\gamma_{d}^{s}$ parameter is determined from the slope of the straight line obtained by the plot of the variation of the adsorption free energy versus the number of carbon atoms for an alkane series [24].

The nanomorphological index $\mathrm{I}_{\mathrm{M}}\left(\chi_{\mathrm{t}}\right)$ can be calculated by injection of cyclic alkanes and this parameter gives information about the regularity of the solid surface at the molecular scale [25].

- The specific component of the surface energy, $\mathrm{I}_{\mathrm{sp}}$, can be determined by injections of polar probes, and gives information about polar interactions developed by the solid surface [25]. Experimentally, the parameter $I_{\mathrm{sp}}$ is determined from the difference between the global free energy of the injected polar probe and the straight line of alkane probes.

\subsection{Inverse gas chromatography at finite concentration (IGC-FC)}

In the case of IGC-FC, a few microliters of a liquid probe are injected into a column containing the solid to be analyzed, in order to provide an approximately mono-layered coverage on the surface of the solid. The results of this technique reflect the interactions of probe molecules with all the sites on the solid surface.

\subsubsection{The desorption isotherm}

Experimentally, the "elution characteristic point" method (ECP) was used, allowing the acquisition of the desorption isotherm from a unique chromatographic peak. The first derivative of the adsorption isotherm can be readily calculated from the net retention time of each characteristic point of the diffuse real front of the chromatogram, according to Conder's equation (Eq. (1)) [26].

$$
\left(\frac{\partial N}{\partial P}\right)_{L . t}=\frac{J D_{c}\left(t_{r}-t_{0}\right)}{m R T}
$$

where, for a given characteristic point, $\mathrm{N}$ is the number of desorbed probe molecules, $\mathrm{P}$ the partial pressure of the probe at the output of the column (directly related to the height of the signal), $t_{r}$ the retention time, $t_{0}$ the dead retention time of methane (a non-adsorbed molecule), $\mathrm{D}_{\mathrm{C}}$ the corrected flow rate, $\mathrm{m}$ the mass of the solid in the column, $\mathrm{L}$ the column length, $\mathrm{R}$ the universal gas constant and $\mathrm{T}$ the oven temperature.

Integration of Conder's equation provides the desorption isotherm, the pressure of the probe being directly related to the height of the signal for each point of the diffuse real front of the chromatogram. The specific surface area and BET constant were determined using the inverse Langmuir calculation method [27].

Due to the presence of highly energetic sites of adsorption, it is generally observed that a non-negligible part of the injected probe is not necessarily eluted in time for the return of the signal to the initial base line. In order to assess this irreversibly adsorbed 
amount, the temperature of the chromatograph oven was increased up to the conditioning temperature, leading to the appearance of a small secondary peak. This gives an assessment of the irreversible part of the adsorption phenomenon from the ratio of the area of the thermodesorption peak with respect to the total area of the chromatogram, giving an irreversibility index $\left(\mathrm{I}_{\text {irr }}\right)$, as previously defined by Balard [27].

\subsubsection{The surface heterogeneity}

A solid surface is always heterogeneous; this heterogeneity can be generated by the morphology (as with a lamellar structure), by the faces of a crystal lattice structure, or by chemical groups. The chromatogram obtained in the IGC-FC conditions allows access to the surface heterogeneity through the calculation of the adsorption energy distribution function for a given probe. Depending of the nature of the probe (an alkane or a polar probe), the morphological or chemical heterogeneity is determined from the analysis of the isotherm shape. The calculation of the distribution function is based on a physical patchwork model given that the global isotherm can be considered as the sum of local isotherms of adsorption on isoenergetic domains.

However, IGC-FC analyses are generally made above room temperature and the condensation approximation is then no longer correct. Rudzinski [28] proposed another method allowing the calculation of the so-called DFRJs (distribution function in the Rudzinski-Jagiello model) through a limited development of the even derivatives of the DFCA (distribution function in the condensation approximation), corrected for the lateral interaction energy. Balard $[27,29]$ described a signal treatment method based on Fourier's transform to calculate the DFRJ up to the order 4.

The surface heterogeneity can be quantified by the surface heterogeneity index, $\mathrm{I}_{\text {hete }}$, expressed in Eq. (2):

$I_{\text {hete }}=100 \frac{A_{\text {exp }}-A_{\text {homo }}}{A_{\exp }}$

Where $A_{\exp }$ is the area under the experimental DF and $A_{\text {homo }}$ is that under the homogeneous DF.

This allows the comparison of the computed DF with the DF describing a homogeneous surface that fits the left descending branch of the experimental DF towards the lowest interaction energies [27].

The distribution functions were computed using special software from the ADSCIENTIS company (Wittelsheim, France).

\section{Materials and methods}

\subsection{Materials}

Montmorillonite (MMT) used as raw material was obtained from the Maghnia deposit (western Algeria), and provided by the ENOF Company (Algeria). Its cation exchange capacity of $86.5 \times 10^{-5}$ $\mathrm{eq} / \mathrm{g}$ was determined according to the sodium acetate saturation method. A quantity of $20 \mathrm{~g}$ of MMT clay was suspended in $500 \mathrm{~mL}$ of $\mathrm{NaCl} 1 \mathrm{M}$. After several hours of stirring, the suspension was left to decant and the supernatant was discarded. The process was repeated 3 times. Then the solid was washed with de-ionized water to remove chloride ions (until $\mathrm{AgNO}_{3}$ test was negative). The resulting chloride-free suspension was diluted in more de-ionized water, homogenized and left to decant in a test tube for $24 \mathrm{~h}$. Then the upper $20 \mathrm{~cm}$ was collected (i.e. clay sample fraction $<2 \mu \mathrm{m}$ ). The product was dried at $358 \mathrm{~K}$ to yield MMT Na+.

Chitosan (CS) (Degree of Deacetylation $=80 \%$ determined by $1 \mathrm{H}$ NMR and molecular weight $293000 \mathrm{~g} / \mathrm{mol}$ determined by Size exclusion chromatography) was purchased from France-Chitine, France.
The acetic acid used for dissolution of CS was provided by the Merck Company and had 99\% purity. The probes employed for IGC were apolar alkanes: n-pentane (C5), n-hexane (C6), nheptane (C7), $n$-octane (C8); a cyclic alkane: cycloheptane (Cy7) and polar probes (dichloromethane $\mathrm{CH}_{2} \mathrm{Cl}_{2}$ and isopropanol (IP)). These probes had a chromatographic grade (>99\%) purity.

\subsection{Preparation of bionanocomposites}

Chitosan-montmorillonite (CSMMT) bionanocomposites were prepared according to the protocol described by Darder [2].

MMT $\mathrm{Na}^{+}$suspension was prepared by dispersing appropriate amount of MMT $\mathrm{Na}^{+}$into $100 \mathrm{~mL}$ of de-ionized water. CS powder was dissolved into a $1 \% \mathrm{v} / \mathrm{v}$ acetic acid solution at $303 \mathrm{~K}$ for $6 \mathrm{~h}$ in order to obtain an aqueous chitosan solution using magnetic stirring at $800 \mathrm{rpm}$. The $\mathrm{pH}$ of solutions was adjusted to 4.9 with a $\mathrm{NaOH}$ solution $(0.1 \mathrm{M})$. Afterwards, the CS solutions were slowly added to the clay suspension at $333 \mathrm{~K}$ under continuous stirring with CS to MMT mass ratios of $0.1 / 1,0.5 / 1,1 / 1$ and $2 / 1$, respectively. The CSMMT mixtures were continuously stirred for $48 \mathrm{~h}$ and then washed with distilled water to remove the acetate salt that remained in the solution. Finally the obtained CSMMT bionanocomposites were dried at $333 \mathrm{~K}$ for $24 \mathrm{~h}$ at atmospheric pressure, and ground to powder.

\subsection{Analysis}

X-ray diffractograms were obtained using a PANanalytical X'Pert Pro MPD diffractometer (Bragg-Brentano set-up). Diffraction data were acquired by exposing the powder samples to $\mathrm{Cu}-\mathrm{K} \alpha$ radiation, which has a wavelength of $1.5418 \AA$. The generator was set to $45 \mathrm{kV}$ and to a current of $40 \mathrm{~mA}$. The data were collected over a range of $5-25^{\circ} 2 \theta$ with a step size of $0.03^{\circ} 2 \theta$ and a nominal time per step of $100 \mathrm{~s}$, using the scanning X'Celerator detector.

Thermogravimetric analyses (TG/DTA) of samples were performed using an TGA-DSC 111 Setaram analyzer with a nitrogen flow rate at $50 \mathrm{~mL} / \mathrm{min}$ and a heating rate of $278 \mathrm{~K} / \mathrm{min}$ from ambient temperature to $773 \mathrm{~K}$.

Particle morphology was investigated using a scanning electron microscope (SEM) (Philips XL 30 model ESEM-FEG) operating at $10 \mathrm{kV}$.

The IR spectra of samples were obtained by transmittance on a $\mathrm{KBr}$ disc using a Nicolet iS10 Fourier transform infrared (FTIR) spectrophotometer from the ThermoFisher Scientific Company. About 2-3 $\mathrm{mg}$ of the sample was mixed with $100 \mathrm{mg}$ of dry potassium bromide and the mixture was submitted to a $73.5 \mathrm{kPa}$ pressure using a hydraulic press to obtain a translucent disc. The samples were scanned from 4000 to $400 \mathrm{~cm}^{-1}$ wave numbers with a resolution of $4 \mathrm{~cm}^{-1}$.

The specific surface areas were measured from nitrogen adsorption isotherms obtained at $77 \mathrm{~K}$ with a 3Flex Surface Characterization Analyser (Micromeritics) applying the BET method. The samples were previously out-gassed under vacuum at $303 \mathrm{~K}$ for $24 \mathrm{~h}$.

Elemental analyses of MMT $\mathrm{Na}^{+}$, CS and CSMMT bionanocomposite samples were investigated by XPS. Spectra were obtained with a KRATOS Axis Ultra X-ray photoelectron spectrometer (Kratos Analytical, Manchester, UK) equipped with a monochromated $\mathrm{Al} \mathrm{K} \alpha \mathrm{X}$-ray ( $\mathrm{h} v=1486.6 \mathrm{eV}$ ) operating at $120 \mathrm{~W}$. The samples were pressed into a $\mathrm{Cu}$ tape fixed on a holder, and then pumped overnight in the fast-entry lock at $10^{-9}$ mbar before introduction in the analysis chamber. Spectra were collected at normal take-off angle $\left(90^{\circ}\right)$ and the analysis area was $700 \times 300 \mu \mathrm{m}^{2}$. The spectra were acquired in the constant analyzer energy mode, with a pass energy of 160 and $20 \mathrm{eV}$ for the survey and the narrow regions, respectively. Charge correction was carried out using the $\mathrm{C} 1 \mathrm{~s}$ core 
Table 1

Results of thermogravimetric analysis.

\begin{tabular}{lll}
\hline Samples & $\begin{array}{l}\text { Weight loss } \\
\text { at 293-453 K } \\
(\%)\end{array}$ & $\begin{array}{l}\text { Weight loss } \\
\text { at 453-723 K } \\
(\%)\end{array}$ \\
\hline MMT Na $^{+}$ & 9.5 & 0.5 \\
CS & 10.0 & 44.8 \\
CSMMT $0.1 / 1$ & 4.5 & 4.2 \\
CSMMT 0.5/1 & 6.6 & 5.6 \\
CSMMT $1 / 1$ & 5.5 & 7.4 \\
CSMMT 2/1 & 4.2 & 9.3 \\
\hline
\end{tabular}

line, setting the adventitious carbon signal ( $\mathrm{H} / \mathrm{C}$ signal) to $284.6 \mathrm{eV}$. The core levels were reported from the peak maxima and had an experimental error of $\pm 0.01 \mathrm{eV}$. These analyses were conducted by the LCPME in Villers-lès-Nancy (France).

The IGC experiments were performed with two Agilent 7890A and 6890 gas chromatographs, equipped with a flame ionization detection (FID) system. Helium was used as the carrier gas with a flow rate of about $30 \mathrm{~mL} / \mathrm{min}$ measured with an electronic flowmeter (Flow500-Agilent). The temperatures of the injector and detector were respectively $423 \mathrm{~K}$ and $443 \mathrm{~K}$. Methane was used as a non-interacting probe.

The IGC-ID study was made with oven temperatures of $383 \mathrm{~K}$ for both MMT Na+ and CSMMT bionanocomposites. For CS, the temperature was fixed at $313 \mathrm{~K}$. The MMT and bionanocomposite columns were conditioned overnight at $393 \mathrm{~K}$ and the CS column at $373 \mathrm{~K}$. The chromatographic columns were $5 \mathrm{~cm}$ in length with $6.35 \mathrm{~mm}$ in internal diameter for $\mathrm{MMTNa}^{+}$and CSMMT bionanocomposites.

For IGC-FC, the chromatographic columns were stainless steel tubes of $5 \mathrm{~cm}$ in length and $6.35 \mathrm{~mm}$ inside diameter. The conditioning temperature was $403 \mathrm{~K}$ and the analysis temperature depended on the probe used, according to the Conder [26] criterion which states that the contribution of probe vapor to the total flow of carrier gas at the maximum of the chromatographic peak should not exceed $5 \%$ of the initial flow. Two probes were analyzed in IGC-FC, octane (C8) at $333 \mathrm{~K}$ and isopropanol (IP) at $313 \mathrm{~K}$.

The injections of each probe were repeated three times and three columns were made with each sample, so as to take into account the heterogeneity of the solid. The quantities after the sign $( \pm)$ in the values tables correspond to the standard deviation from duplicate measurements.

\section{Results and discussion}

\subsection{Thermogravimetric analysis}

The results of TGA of MMT $\mathrm{Na}^{+}, \mathrm{CS}$ and CSMMT bionanocomposites are given in Table 1. Two significant mass losses are observed for CS, namely 10 and $44.8 \%$. These two mass losses were attributed respectively to water loss and to decomposition of the polymer via deacetylation-depolymerization. Similar results have been reported by other researchers [30,31]. MMT Na ${ }^{+}$shows a $9.5 \%$ mass loss between 293 and $453 \mathrm{~K}$, which is associated to water desorption from the interlayer space and a thermic stability between 453 and $723 \mathrm{~K}$.

However, CSMMT bionanocomposites show mass losses ranging from 4.2 to $9.3 \%$ between 453 and $723 \mathrm{~K}$. This result indicates the high thermal stability of bionanocomposites. This thermal stability is attributed to the thermal insulation behavior induced by the CS insertion between MMT Na+ layers and to changes in the dynamics of molecular motion in bionanocomposites [32].
Table 2

Values of specific surface areas ( $\left.\mathrm{a}_{\mathrm{BET}}\right)$, BET constants $\left(\mathrm{C}_{\mathrm{BET}}\right)$ for $\mathrm{CS}, \mathrm{MMT} \mathrm{Na}^{+}$and bio-nanocomposites.

\begin{tabular}{lll}
\hline Samples & $\mathrm{a}_{\mathrm{BET}}\left(\mathrm{m}^{2} / \mathrm{g}\right)$ & $\mathrm{C}_{\mathrm{BET}}$ \\
\hline MMT Na $^{+}$ & $77.1 \pm 4.3$ & $886 \pm 42$ \\
CSMMT 0.1/1 $_{\text {CSMMT 0.5/1 }}$ & $65.8 \pm 3.5$ & $575 \pm 54$ \\
CSMMT $1 / 1$ & $55.5 \pm 2.9$ & $360 \pm 25$ \\
CSMMT 2/1 & $37.1 \pm 2.7$ & $231 \pm 59$ \\
CS & $26.5 \pm 2.1$ & $343 \pm 43$ \\
\hline
\end{tabular}

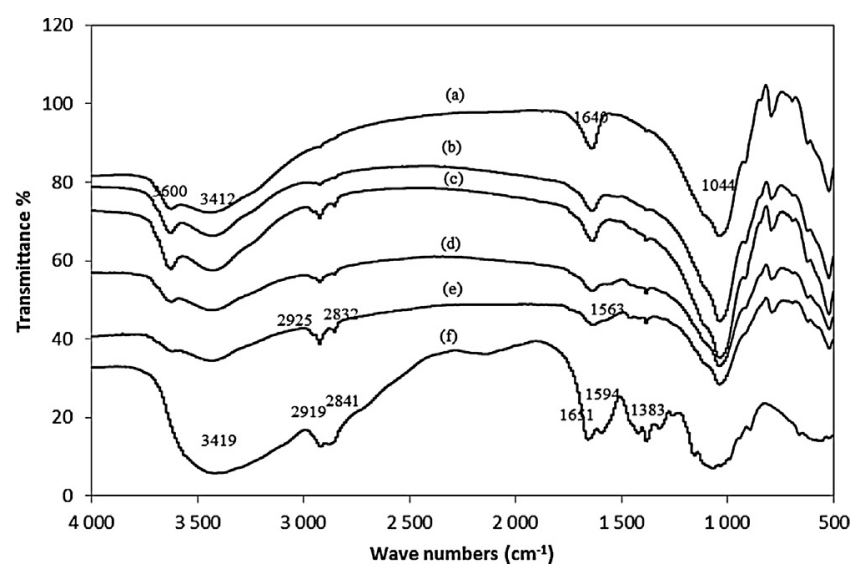

Fig. 1. FT-IR spectra of (a) MMT Na ${ }^{+}$, (b) CSMMT 0.1/1, (c) CSMMT 0.5/1, (d) CSMMT $1 / 1$, (e) CSMMT $2 / 1$ and (f) CS

\subsection{BET surface analysis}

Values of specific areas and BET constants obtained by $\mathrm{N}_{2}$ adsorption are given in Table 2.

The results clearly show a decrease in the specific surface area of bionanocomposites with the increase of CS mass ratio. This decrease can be attributed to the compact packing of the CS molecules in the interlayer space, resulting in the blocking of pores, which prevents the adsorption of nitrogen molecules [33].

At the same time, the values of $C_{B E T}$ generally decrease with the decrease in the specific surface area. The interactions between nitrogen and MMT Na+ are lower in the presence of CS.

\subsection{FT-IR analysis}

The FT-IR spectra of CS, MMT $\mathrm{Na}^{+}$and CSMMT bionanocomposites are shown in Fig. 1.

The absorption bands from FT-IR spectrum of MMT $\mathrm{Na}^{+}$were assigned as follow: 3600 and $3412 \mathrm{~cm}^{-1}$ correspond to $\mathrm{OH}$ stretching vibrations in molecular waters and in MMT Na+ to Si-OH and Al-OH bonds, $1640 \mathrm{~cm}^{-1}$ corresponds to the bending vibrations of water and at $1044 \mathrm{~cm}^{-1}$ to $\mathrm{Si}-\mathrm{O}$ stretching in $(\mathrm{SiO})^{4-}$ tetrahydra.

The IR spectrum of CS Exhibits - $\mathrm{OH}$ stretching vibration at around $3419 \mathrm{~cm}^{-1}$ and bands at 2919 and $2841 \mathrm{~cm}^{-1}$ assigned to aliphatic $\mathrm{C}-\mathrm{H}$ stretching [33]. An absorption band with a maximum at $1594 \mathrm{~cm}^{-1}$ belongs to free primary amino group bending $\left(\mathrm{NH}_{2}\right)$ at $\mathrm{C} 2$ position of glucosamine, which is a major group present in CS. The peak at $1651 \mathrm{~cm}^{-1}$ is assigned to the acetylated amino group in CS. Another peak at $1383 \mathrm{~cm}^{-1}$ is attributed to a $\mathrm{C}-\mathrm{H}$ bending vibration.

Bionanocomposites possess characteristic bands at approximately 2925 and $2832 \mathrm{~cm}^{-1}$ corresponding to the stretching vibrations of CS $\mathrm{C}-\mathrm{H}$. The band attributed to the bending vibration of the CS C-H methylene group $\left(1380 \mathrm{~cm}^{-1}\right)$ is also observed in the spectra of the bionanocomposites. 


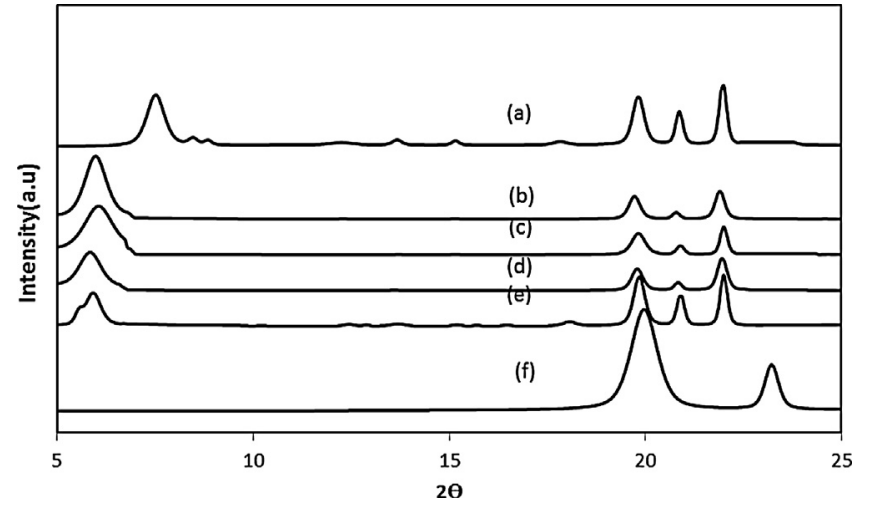

Fig. 2. XRD patterns of (a) MMT $\mathrm{Na}^{+}$, (b) CSMMT 0.1/1, (c) CSMMT 0.5/1, (d) CSMMT $1 / 1$, (e) CSMMT $2 / 1$ and (f) CS.

The peak at $1594 \mathrm{~cm}^{-1}$ of the $-\mathrm{NH}_{2}$ groups in CS was shifted to $1563 \mathrm{~cm}^{-1}$ in CSMMT $2 / 1$ bionanocomposite spectrum, corresponding to the deformation vibration of the protonated amine group $\left(-\mathrm{NH}_{3}^{+}\right)$of $\mathrm{CS}$ resulting from its dissolution in acetic acid. This $-\mathrm{NH}_{3}^{+}$group will interact with the negatively-charged sites of MMT $\mathrm{Na}^{+}$and will be at the origin of strong interactions between the two components.

\subsection{XRD analysis}

XRD analysis was also implemented for the characterization of polymer/clay nanocomposites. It allows the distance between the silicate plates to be measured and makes it possible to observe the intercalation of the polymer chains [34]. Fig. 2 illustrates XRD patterns of MMT $\mathrm{Na}^{+}$, CS and CSMMT bionanocomposites. Considering the XRD pattern of MMT Na${ }^{+}$, the peak at $2 \theta=7.545^{\circ}$ corresponds to a d $\mathrm{d}_{001}$ spacing of $11.8 \mathrm{~nm}$. Structural changes of the $\mathrm{MMT} \mathrm{Na}^{+}$upon CS incorporation are clearly observed from this characteristic $\mathrm{d}_{001}$ diffraction peak. The $\mathrm{d}_{001}$ spacing increases slightly from $11.8 \mathrm{~nm}$ for MMT Na+ to $14.65,14.75,14.80,15.05,15.45 \mathrm{~nm}$ for $0.1 / 1,0.5 / 1$, $1 / 1$ and 2/1 CSMMT bionanocomposites respectively, indicating the MMT $\mathrm{Na}^{+}$interlayer expansion, which can be reasonably ascribed to the intercalation of CS in the MMT $\mathrm{Na}^{+}$interlayer region.

Moreover, the movement of the diffraction peak at $2 \theta=7.545^{\circ}$ for pure MMT to a lower angle for CS bionanocomposites indicates the formation of an intercalated nanostructure, whereas the peak broadening and intensity decrease suggest, for the CSMMT 2/1 sample, the presence of a disordered intercalated or exfoliated structure [11].

\subsection{Surface chemical composition}

The surface composition of MMT $\mathrm{Na}^{+}$, CS and CSMMT bionanocomposites was monitored by XPS, as this technique can probe the surface of samples and detect subtle changes in the chemical composition of the surface.

Fig. 3 displays XPS survey spectra of electron intensity as a function of bending energy for MMT $\mathrm{Na}^{+}, \mathrm{CS}$ and the CSMMT bionanocomposites.

For MMT $\mathrm{Na}^{+}$(Fig. 3a), the main peaks are $\mathrm{Si} 2 \mathrm{p}(103 \mathrm{eV}), \mathrm{Al} 2 \mathrm{p}$ (131 eV), C1 s (285 eV), Mg (KLL) (305 eV), Na (KLL) (500 eV), O1 s (531 eV), O (KLL) $(979 \mathrm{eV})$, and Na1 s (1071 eV).

The XPS spectrum of CS (Fig. 3d) reveals that carbon and oxygen are the major elements, which occurs about 284 and $532 \mathrm{eV}$, respectively, and there is a small amount of nitrogen at $398 \mathrm{eV}$ with some impurities.

While, CSMMT bionanocomposites have a survey scan similar to that of the corresponding untreated MMT $\mathrm{Na}^{+}$, with the

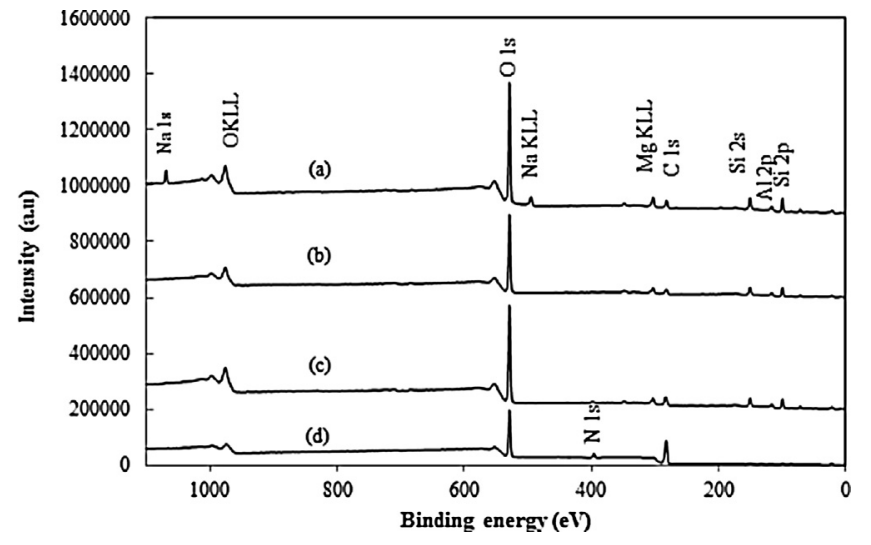

Fig. 3. XPS spectra of (a) MMT Na+, (b) CSMMT 0.1/1, (c) CSMMT 2/1 and (d) CS.

MMT $\mathrm{Na}^{+}$characteristic peaks of $\mathrm{Si}, \mathrm{Al}, \mathrm{Mg}$, a qualitative indication that the bionanocomposite surface is MMT-rich (Fig. 3b, c). The same results were obtained by Boukerma for polypyrrole/montmorillonite nanocomposites [22]. However, the scan reveal the $\mathrm{Na}^{+}-\mathrm{CS}$ cation exchange by the disappearance of the two peaks corresponding to $\mathrm{Na}$ at 500 and $1071 \mathrm{eV}$, in the bionanocomposites.

For a clearer understanding, the peaks of $\mathrm{N} 1 \mathrm{~s}$ and $\mathrm{C} 1 \mathrm{~s}$ spectra have been deconvoluted for MMT $\mathrm{Na}^{+}, \mathrm{CS}$ and CSMMT $2 / 1$ samples (Figs. 4 and 5).

Fig. 4a shows the deconvolution of N1s spectrum for CS sample, the broad at 399-402 eV includes two peaks at bending energies of 399.10 and $399.91 \mathrm{eV}$, respectively. The peak located at $399.10 \mathrm{eV}$ is assigned to $\mathrm{N}$ atoms bonded with $\mathrm{C}$ atoms and the peak at $399.91 \mathrm{eV}$ is attributed to $\mathrm{C}-\mathrm{NH}_{3}^{+}$bending. The peak of $\mathrm{N} 1 \mathrm{~s}$ in CS illustrates a larger contribution of neutral $\mathrm{N}$ and a relatively smaller contribution of positively charged $\mathrm{N}^{+}$.

In the case of CSMMT 2/1 bionanocomposite (Fig. 4b), the deconvolution of N1s spectrum shows the same two peaks as for CS. But the peak located at $399.91 \mathrm{eV}$ assigned to $\mathrm{NH}_{3}^{+}$, in $\mathrm{CS}$ has shifted to $402.17 \mathrm{eV}$. As indicated with IR spectroscopy results, this $-\mathrm{NH}_{3}^{+}$ group is at the origin of strong interactions with the negatively charged sites of MMT $\mathrm{Na}^{+}$.

The assignment of deconvoluted high resolution XPS of $\mathrm{C} 1 \mathrm{~s}$ peak in CS, MMT $\mathrm{Na}^{+}$and CSMMT 2/1 bionanocomposite is displayed in Fig. 5.

The peak of $\mathrm{C} 1 \mathrm{~s}$ in $\mathrm{MMT} \mathrm{Na}^{+}$results from the presence of organic carbon. The deconvolution of the $\mathrm{C} 1 \mathrm{~s}$ spectrum in $\mathrm{MMT} \mathrm{Na}^{+}$(Fig. 5a) leads to four peaks centred at 284.59, 285.74, 286.99 and $289.14 \mathrm{eV}$ attributed to $\mathrm{C} 1(\mathrm{C}-\mathrm{H} / \mathrm{C}-\mathrm{C}), \mathrm{C} 2(\mathrm{C}-\mathrm{O} / \mathrm{C}-\mathrm{OH}), \mathrm{C} 3(\mathrm{O}-\mathrm{C}-\mathrm{O})$ and $\mathrm{C} 4$ $(\mathrm{O}-\mathrm{C}=\mathrm{O})$, respectively [35]. The spectrum reveals the higher contribution of $\mathrm{C}-\mathrm{H}$ than other forms of carbon bonds.

For CS, the $\mathrm{C} 1 \mathrm{~s}$ spectrum (Fig. $5 \mathrm{~b}$ ) is deconvoluted in four peaks located at 284.61, 286.11,287.76, $289.31 \mathrm{eV}$, assigned to $\mathrm{C} 1(\mathrm{C}-\mathrm{H} / \mathrm{C}-\mathrm{C}), \mathrm{C} 2(\mathrm{C}-\mathrm{O} / \mathrm{C}-\mathrm{N} / \mathrm{C}-\mathrm{O}-\mathrm{C}), \mathrm{C} 3(\mathrm{C}=\mathrm{O})$ and $\mathrm{C} 4(\mathrm{~N}-\mathrm{C}=\mathrm{O})$ respectively. The $(\mathrm{C}-\mathrm{O} / \mathrm{C}-\mathrm{N} / \mathrm{C}-\mathrm{O}-\mathrm{C})$ peak is more pronounced than the other peaks.

As regards the CSMMT 2/1 bionanocomposite, its spectrum (Fig. 5c) also reveals four bands, $\mathrm{C} 1(\mathrm{C}-\mathrm{H} / \mathrm{C}-\mathrm{C}), \mathrm{C} 2(\mathrm{C}-\mathrm{O} / \mathrm{C}-\mathrm{N} / \mathrm{C}-\mathrm{O}-$ $\mathrm{C}), \mathrm{C} 3(\mathrm{C}=\mathrm{O})$ and $\mathrm{C} 4(\mathrm{~N}-\mathrm{C}=\mathrm{O})$ at $284.62,286.52,288.17$ and $289.27 \mathrm{eV}$, respectively. Yang [36] suggested that the carboxylate carbon peak present in MMT at $289.14 \mathrm{eV}$ has been replaced by an amide peak at $289.27 \mathrm{eV}$, indicating that chitosan was adsorbed onto MMT Na${ }^{+}$through the reaction of amino groups with carboxylate groups.

Table 3 shows that the weight percentages of nitrogen and carbon atoms, the major elements in the chemical composition of CS (except the oxygen), increase with the increasing CS mass ratio, 

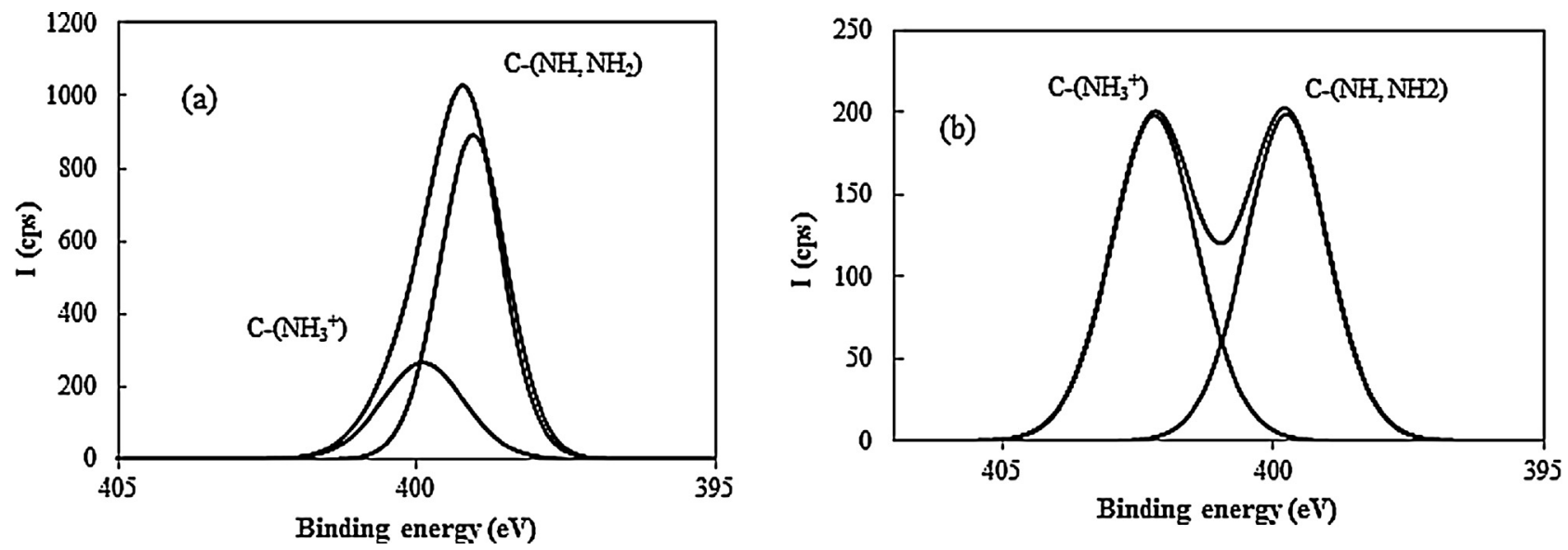

Fig. 4. N1s high resolution regions of (a) CS, (b) CSMMT 2/1.
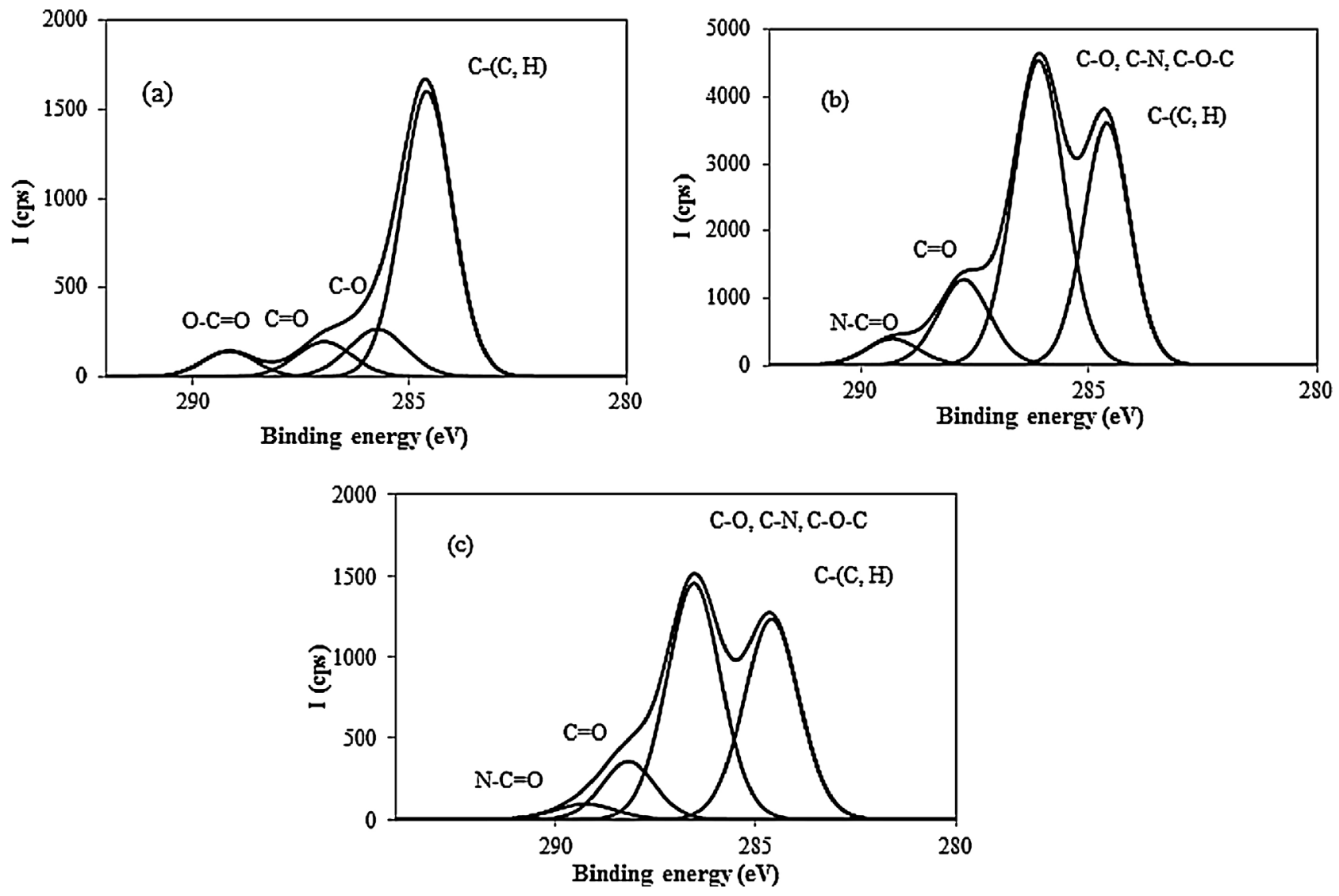

Fig. 5. $\mathrm{C} 1 \mathrm{~s}$ high resolution regions of (a) $\mathrm{MMT} \mathrm{Na}^{+}$, (b) CS, (c) CSMMT 2/1.

Table 3

Surface chemical composition of MMT Na+, CS and bionanocomposites obtained by XPS.

\begin{tabular}{|c|c|c|c|c|c|c|c|c|c|}
\hline & $\mathrm{O}$ & $\mathrm{N}$ & $\mathrm{C}$ & $\mathrm{Na}$ & $\mathrm{Ca}$ & $\mathrm{Si}$ & $\mathrm{Al}$ & $\mathrm{Mg}$ & $\mathrm{Fe}$ \\
\hline CS & 38.08 & 5.87 & 53.58 & - & 1.61 & 0.86 & - & - & - \\
\hline MMT Na ${ }^{+}$ & 48.99 & - & 6.12 & 3.83 & 0.95 & 26.63 & 10.2 & 2 & 1.28 \\
\hline CSMMT 0.1/1 & 48.38 & 0.35 & 8.79 & - & 0.63 & 26.25 & 11.22 & 2.14 & 2.24 \\
\hline CSMMT $0.5 / 1$ & 47.96 & 0.84 & 12.86 & - & 0.35 & 25.42 & 9.89 & 1.36 & 1.32 \\
\hline CSMMT $1 / 1$ & 47.34 & 0.95 & 15.29 & - & 0.26 & 23.95 & 9.38 & 1.61 & 1.22 \\
\hline CSMMT 2/1 & 46.41 & 1.46 & 16.98 & - & 0.29 & 23.44 & 8.73 & 1.57 & 1.12 \\
\hline
\end{tabular}

while at the same time those of the $\mathrm{Si}, \mathrm{Al}, \mathrm{Mg}$ and $\mathrm{Fe}$ atoms characteristic of MMT $\mathrm{Na}^{+}$decrease slightly.
Table 3 The $\mathrm{C} / \mathrm{Si}$ atomic ratio increases progressively with the increase of CS in bionanocomposites, namely 0.28, 0.30, 0.51, 0.59, 
Table 4

Values of $\gamma_{s}^{d}, \mathrm{I}_{\mathrm{M}}\left(\chi_{t}\right)$ and $\mathrm{I}_{\mathrm{sp}}$ of MMT Na ${ }^{+}$, CS and CSMMT bionanocomposites.

\begin{tabular}{llll}
\hline & $\gamma_{s}^{d}\left(\mathrm{~mJ} / \mathrm{m}^{2}\right)\langle b r\rangle$ & $I_{M}\left(\chi_{t}\right) \mathrm{Cycl} 7$ & $I_{s p} \mathrm{CH}_{2} \mathrm{Cl}_{2}(\mathrm{~kJ} / \mathrm{mol})$ \\
\hline MMT Na $^{+}$ & $184 \pm 4$ & $0.06 \pm 0.01$ & $16.7 \pm 0.7$ \\
CSMMT 0.1/1 & $160 \pm 4$ & $0.08 \pm 0.02$ & $15.5 \pm 0.9$ \\
CSMMT 0.5/1 & $149 \pm 4$ & $0.12 \pm 0.03$ & $12.8 \pm 0.6$ \\
CSMMT 1/1 & $119 \pm 3$ & $0.20 \pm 0.01$ & $12.7 \pm 0.6$ \\
CSMMT 2/1 & $90 \pm 3$ & $0.26 \pm 0.02$ & $11.3 \pm 0.5$ \\
CS $^{\text {a }}$ & $46 \pm 1$ & $0.98 \pm 0.02$ & $10.2 \pm 0.4$ \\
\hline
\end{tabular}

a Analyzed at $323 \mathrm{~K}$.

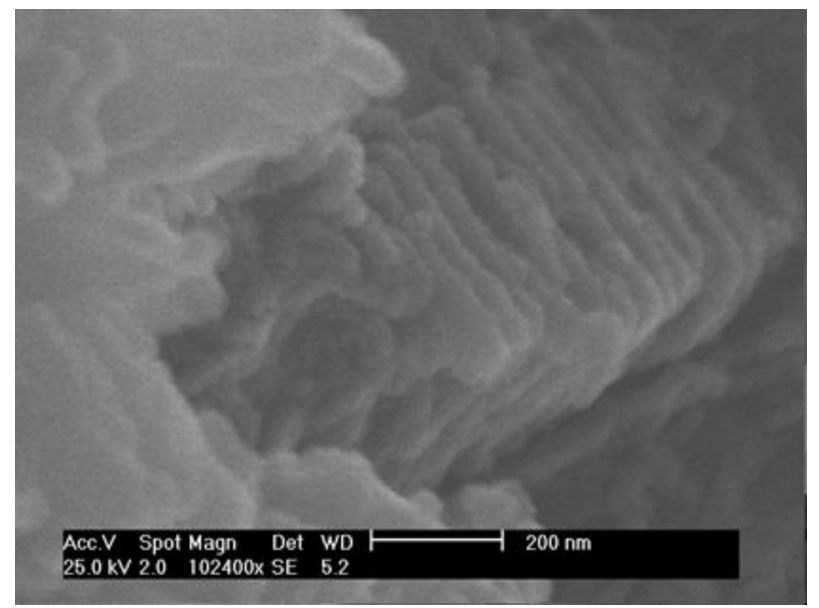

Fig. 6. SEM micrographs of MMT $\mathrm{Na}^{+}$.

0.71 and 16.53 for MMT $\mathrm{Na}^{+}$, CSMMT 0.1/1, CSMMT 0.5/1, CSMMT $1 / 1$, CSMMT 2/1 and CS respectively. All these results obtained by XPS analysis indicate that CS is essentially confined in the interlamellar space of the clay particles and CSMMT bionanocomposites were synthesized successfully.

\subsection{Surface properties by inverse gas chromatography (IGC)}

\subsubsection{IGC at infinite dilution (IGC-ID)}

The dispersive component of the surface energy, $\gamma_{s}^{d}$, the nanomorphological index, $\mathrm{I}_{\mathrm{M}}\left(\chi_{\mathrm{t}}\right)$, and the specific interactions parameter, $\mathrm{I}_{\mathrm{sp}}$, obtained by IGC-ID for MMT $\mathrm{Na}^{+}$, and four bionanocomposites at $383 \mathrm{~K}$ and CS at $323 \mathrm{~K}$ are listed in Table 4. The $323 \mathrm{~K}$ analysis temperature for CS was chosen due to its degradation at $383 \mathrm{~K}$, and to its very fast elution above $323 \mathrm{~K}$.

For MMT $\mathrm{Na}^{+}$, the high value of $\gamma_{s}^{d}$ is typical of lamellar solids. It reflects the insertion of linear alkanes into the space between the sheets stacking of the phyllosilicate (Fig. 6). This value is in agreement with those obtained in the literature, for instance by Bandosz et al. [37], namely $155 \mathrm{~mJ} / \mathrm{m}^{2}$ at $423 \mathrm{~K}$ for untreated MMT or by Mravčáková [38], namely $216 \mathrm{~mJ} / \mathrm{m}^{2}$ for pure MMT at $423 \mathrm{~K}$, or by Boukerma [22], $114 \mathrm{~mJ} / \mathrm{m}^{2}$ at $423 \mathrm{~K}$ for pure MMT.

The $\gamma_{s}^{d}$ values of CSMMT bionanocomposites decrease with the increasing of the CS mass ratio. This drop may be related to the modification caused by the cation exchange reaction leading to the covering of the active groups of $\mathrm{MMT} \mathrm{Na}^{+}$surface with long-chains CS biopolymer. So the active sites located in the space between the stacked sheets are no longer available for alkane adsorption. Furthermore, the results show that the values of the surface energy correlates with the values of the specific surface area (Fig. 7).

The low $I_{M}\left(\chi_{t}\right)$ of MMT Na ${ }^{+}$corresponds to size exclusion effects. The linear alkane is able to insert itself partially into the porous sites, whereas a cyclic probe such as cyclic alkane (Cy7) is excluded [39].

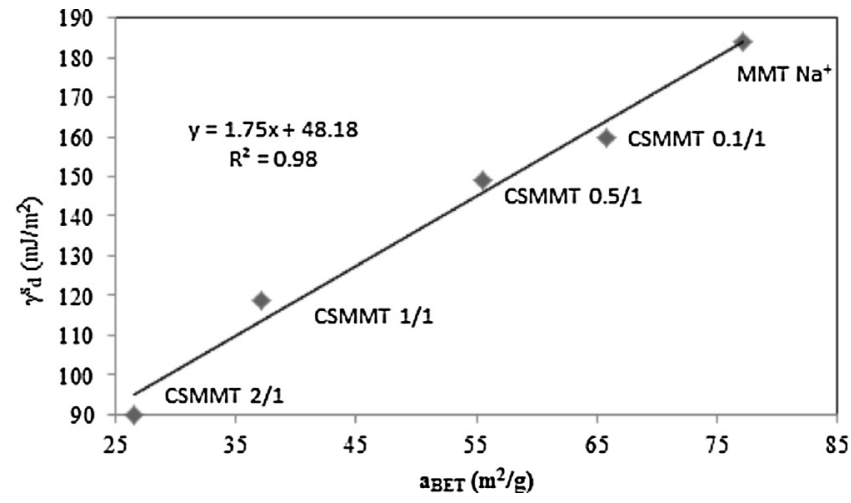

Fig. 7. Plot of $\gamma_{s}^{d}$ (at $383 \mathrm{~K}$ ) versus $\mathrm{a}_{\mathrm{BET}}$ for CSMMT bionanocomposites.

In the case of CSMMT bionanocomposites, the $I_{M}\left(\chi_{t}\right)$ values obtained with the cyclic probe increase slightly with the increasing mass ratio of CS in MMT Na ${ }^{+}$, indicating the progressive disappearance of surface roughness or porosity by adsorption of CS.

Several polar and amphoteric probes, such as acetone and methyl acetate were injected, but due to their strong interactions with the MMT $\mathrm{Na}^{+}$surface, they could not be eluted through the chromatographic column even at $383 \mathrm{~K}$ oven temperature, testifying to the strong energetic character of the MMT Na+ surface due to the presence of amphoteric silanol groups. Strzemiecka et al., also observed strong interactions between fragrance molecules and another aluminosilicate, zeolite [40].

Only the acidic dichloromethane probe was eluted and this was used to calculate the specific interaction parameter $I_{s p}$. This parameter decreases slightly as the CS mass ratio increases. This decrease can be explained by the gradual disappearance of amphoteric sites like silanols consequent to CS adsorption on the MMT Na${ }^{+}$surface or in the space between sheets, as supported by XPS.

\subsection{Inverse gas chromatography at finite concentration (IGC-FC)}

\subsubsection{Study of desorption isotherms}

The desorption isotherm was computed from a chromatogram obtained when the probe monolayer is reached at the solid surface, according to the ECP method. The characteristic parameters obtained by IGC-FC by injecting $n$-octane and isopropanol probes are listed in Table 5 and compared to those obtained with nitrogen adsorption.

It is observed that the specific surface areas measured with nitrogen adsorption are close to those measured with the octane probe.

The BET constants measured using nitrogen adsorption (Table 5) are higher than those obtained by IGC-FC with octane and isopropanol, reflecting a greater affinity of nitrogen to the surface of raw materials and CS/MMT bionanocomposites. This observation may be related to the difference in the analysis temperature, $77 \mathrm{k}$ for nitrogen and $333 \mathrm{~K}$ for octane or $313 \mathrm{~K}$ for isopropanol, so the higher the temperature is, the weaker the interactions between the probe and the surface are, leading to a lower BET constant. Furthermore, it can be observed that whatever the probe used, the BET constant decreases with the increase of CS mass ratio testifying that $\mathrm{N}_{2}$ and the injected probes interact less strongly with the CS/MMT bionanocomposites than with MMT. This behavior is due to the disappearance of high energy sites on MMT hidden by chitosan.

However, the specific surface areas measured with isopropanol are lower than those measured with nitrogen or $n$-octane. The $\mathrm{I}_{\text {irr }}$ values (Table 6) obtained with isopropanol are higher than those with octane, reflecting a higher irreversible adsorption of isopropanol compared to the $n$-octane probe. Isopropanol interacts 
Table 5

Values of the specific surface areas ( $\mathrm{a}_{\mathrm{BET}}$ ) of $\mathrm{MMT} \mathrm{Na}^{+}, \mathrm{CS}$ and CSMMT bionanocomposites samples by nitrogen adsorption and IGC-FC.

\begin{tabular}{|c|c|c|c|c|c|c|}
\hline \multirow[b]{3}{*}{$\mathrm{a}_{\mathrm{BET}}\left(\mathrm{m}^{2} / \mathrm{g}\right)$} & & & \multicolumn{4}{|l|}{ IGC-FC } \\
\hline & \multicolumn{2}{|c|}{ Adsorption $\mathrm{N}_{2}$} & \multicolumn{2}{|l|}{ C8 (333 K) } & \multicolumn{2}{|l|}{ IP (313 K) } \\
\hline & $\mathrm{C}_{\mathrm{BET}}$ & $\mathrm{a}_{\mathrm{BET}}\left(\mathrm{m}^{2} / \mathrm{g}\right)$ & $\mathrm{C}_{\mathrm{BET}}$ & $\mathrm{a}_{\mathrm{BET}}\left(\mathrm{m}^{2} / \mathrm{g}\right)$ & $\mathrm{C}_{\mathrm{BET}}$ & \\
\hline MMT Na+ & $77.1 \pm 4.3$ & $886 \pm 42$ & $72.1 \pm 3.4$ & 17.0 & $69 \pm 3.5$ & 23.1 \\
\hline CSMMT $0.1 / 1$ & $65.8 \pm 3.5$ & $575 \pm 54$ & $60.6 \pm 3.5$ & 13.6 & $52 \pm 3.2$ & 22.5 \\
\hline CSMMT 0.5/1 & $55.5 \pm 2.9$ & $360 \pm 25$ & $49.3 \pm 3.1$ & 14.1 & $43 \pm 2.9$ & 16.3 \\
\hline CSMMT 1/1 & $37.1 \pm 2.7$ & $231 \pm 59$ & $33.6 \pm 2.9$ & 10.2 & $30 \pm 3.0$ & 16.2 \\
\hline CSMMT $2 / 1$ & $26.5 \pm 2.1$ & $343 \pm 43$ & $27.1 \pm 2.9$ & 10.3 & $24 \pm 2.5$ & 12.5 \\
\hline CS & $4.1 \pm 0.2$ & $12 \pm 7$ & $1.5 \pm 0.1$ & 6.2 & $0.9 \pm 0.1$ & 8.3 \\
\hline
\end{tabular}

Table 6

Values of irreversibility indexes $\left(I_{\text {irr }}\right)$ measured using $n$-octane and isopropanol probes on the studied samples.

\begin{tabular}{lll}
\hline & $\mathrm{I}_{\text {irr(C8) }} 333 \mathrm{~K}$ & $\mathrm{I}_{\text {irr(IP) }} 313 \mathrm{~K}$ \\
\hline MMT Na $^{+}$ & $5.6 \pm 0.3$ & $39.2 \pm 4.1$ \\
CSMMT 0.1/1 $_{\text {CSMMT 0.5/1 }}$ & $3.7 \pm 0.1$ & $37.3 \pm 3.7$ \\
CSMMT 1/1 & $2.8 \pm 0.2$ & $26.7 \pm 3.9$ \\
CSMMT 2/1 & $2.1 \pm 0.1$ & $21.4 \pm 3.2$ \\
CS & $1.4 \pm 0.2$ & $12.6 \pm 2.1$ \\
\hline
\end{tabular}

strongly with MMT $\mathrm{Na}^{+}$silanol groups through hydrogen bonds. This irreversible adsorption at analysis temperature contributes to the decrease in the measured specific surface areas computed from the reversible part of the adsorption phenomenon.

Comparing the influence of CS mass ratio in bionanocomposites, it is observed that, whatever the probe, the values of $\mathrm{I}_{\text {irr }}$ decrease persistently with the increasing CS mass ratio. This variation with $n$-octane, a probe sensitive to morphology, indicates the disappear-

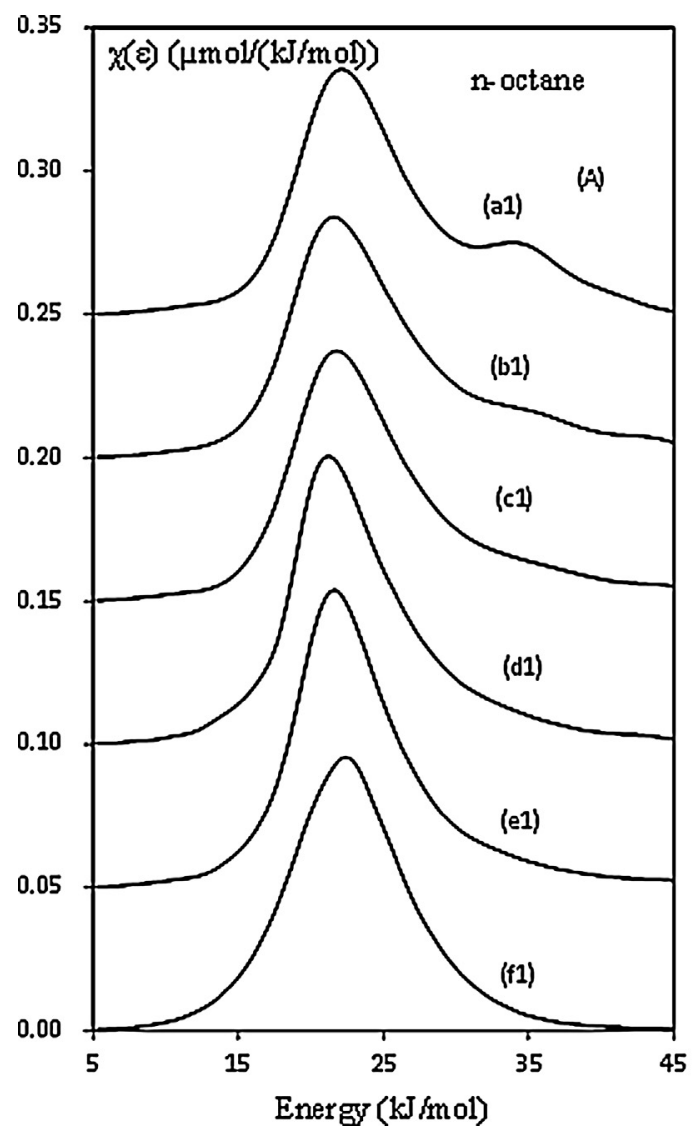

ance of surface roughness, while with the isopropanol, a probe more sensitive to functionality, the disappearance of high energy sites like silanols is more pronounced. The variations of $\mathrm{I}_{\mathrm{irr}}$ obtained with both probes can probably be attributed to the progressive adsorption of CS biopolymer chains inside and/or onto the layered clay, leading to a smoother surface with a covering of the porosity and a disappearance of polar groups.

\subsection{Assessment of the surface energetic heterogeneity}

The heterogeneity of the surface energy of CS, MMT $\mathrm{Na}^{+}$and CSMMT bionanocomposites was estimated by IGC-FC using the distribution functions for both $n$-octane and isopropanol probes (Fig. 8).

The DFs of $n$-octane obtained on MMT Na+, CS and CSMMT bionanocomposites are compared in Fig. 8A. The DF obtained with this linear alkane on the MMT Na+ sample is bimodal. The first peak can

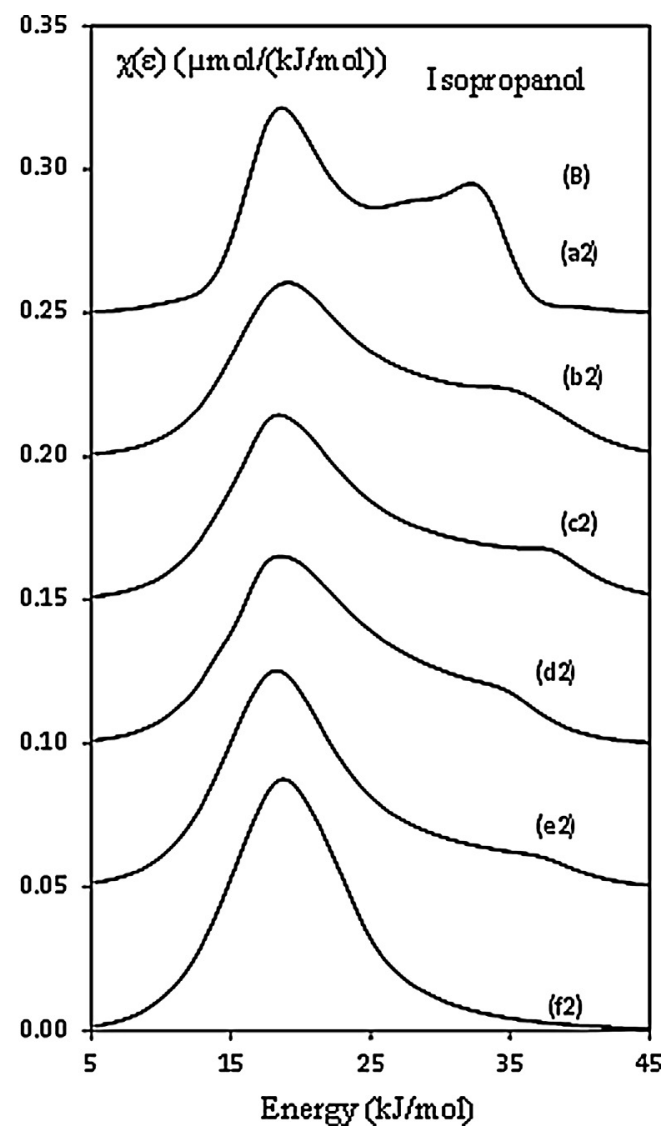

Fig. 8. Adsorption energy distribution functions of the $n$-octane (a1: MMT Na ${ }^{+}$, b1: CSMMT 0.1/1, c1: CSMMT 0.5/1, d1: CSMMT 1/1, e1: CSMMT 2/1 and f1: CS) and isopropanol (a2: MMT Na ${ }^{+}$, b2: CSMMT 0.1/1, c2: CSMMT 0.5/1, d2: CSMMT 1/1, e2: CSMMT 2/1 and f2: CS) measured respectively at $333 \mathrm{~K}$ and $313 \mathrm{~K}$. 
Table 7

Heterogeneity index $\left(\mathrm{I}_{\text {hete }}\right)$ values measured by IGC-FC for $n$-octane and isopropanol on raw materials and bionanocomposites.

\begin{tabular}{lll}
\hline & $\mathrm{I}_{\text {hete(C8) } 333 \mathrm{~K}}$ & $\mathrm{I}_{\text {hete(IP) }} 313 \mathrm{~K}$ \\
\hline MMT Na $^{+}$ & $32 \pm 3$ & $49 \pm 4$ \\
CSMMT 0.1/1 $_{\text {CSMMT 0.5/1 }}$ & $31 \pm 3$ & $44 \pm 4$ \\
CSMMT 1/1 & $26 \pm 3$ & $36 \pm 3$ \\
CSMMT 2/1 & $19 \pm 3$ & $34 \pm 3$ \\
CS & $15 \pm 2$ & $21 \pm 2$ \\
\hline
\end{tabular}

be related to less energetic sites on the flat surface and the second one to high energy sites located in spaces between sheet stackings.

On the other hand, the DFs obtained with CSMMT bionanocomposites samples are monomodal, the DFs obtained become more symmetrical as the CS mass ratio increases, testifying that morphology modification takes place after CS intercalation by a decrease in surface roughness.

The DFs of the isopropanol are different from those obtained by $n$-octane (Fig. 8B). In MMT $\mathrm{Na}^{+}$, the DFs are clearly bimodal, exhibiting a main maximum energy peak between 18 and $20 \mathrm{~kJ} / \mathrm{mol}$ and a larger shoulder centred around $35-40 \mathrm{~kJ} / \mathrm{mol}$. According to Balard [25], the former corresponds to the alcohol/siloxane dispersive interactions and the later to the alcohol/silanol specific interactions, namely hydrogen bridge interactions.

However, the DFs of CSMMT bionanocomposites show a progressive disappearance of the shoulders at high energies with an increase in CS mass ratio, indicating that the sites having the highest energies on the surface or between galleries is replaced by CS chains.

The asymmetry of the DFs can describe the surface heterogeneity by means of an index of heterogeneity. The values were determined for $n$-octane and isopropanol (Table 7). The heterogeneity index values ( $\mathrm{I}_{\text {hete }}$ ) were much higher with isopropanol than with $n$ - octane. These differences highlight the greater ability of isopropanol to detect surface heterogeneity by binding to a polar site.

The values of the heterogeneity index of the both injected probes decrease significantly. This decrease in the heterogeneity indexes is consistent with the progressive adsorption/intercalation of CS in the surface of clay.

\section{Conclusion}

Bionanocomposites based on CS and MMT $\mathrm{Na}^{+}$with different amounts of CS were prepared in a liquid phase and characterized in terms of structural and chemical properties by different techniques.

Among them, XRD patterns indicated that CS were intercalated in the MMT $\mathrm{Na}^{+}$galleries, and the interlayer spacing of clay increased after ion exchanging of $\mathrm{Na}^{+}$with CS. XPS analysis also showed that the surface of the bionanocomposites are MMT-rich despite the intercalation of CS in MMT.

Using IGC at infinite dilution, a surface characterization technique, it was observed that there is a decrease in the dispersive component of the surface energy and correlatively an increase in the nanomorphology index obtained with the cycloheptane probe on the bionanocomposites, testifying the disappearance of high energy sites with the increase in CS mass ratio.
IGC at finite concentration was used to obtain a more realistic description of the whole surface.

The distribution functions obtained with isopropanol, a probe sensitive to chemical functionality, confirmed the modification of MMT Na+ after CS intercalation threw a progressive disappearance of the shoulders at high energy with an increase in CS mass ratio.

\section{References}

[1] E. Ruiz-Hitzky, P. Aranda, M. Darder, Kirk-Othmer Encycl. Chem. Technol. (2008)

[2] M. Darder, M. Colilla, E. Ruiz-Hitzky, Chem. Mater. 15 (2003) 3774-3780.

[3] J. Praveen Kumar, P.V.R.K. Ramacharyulu, G.K. Prasad, Beer Singh, Appl. Clay Sci. 116-117 (2015) 263-272.

[4] E. Eren, B. Afsin, Dyes Pigm. 76 (2008) 220-225.

[5] A. Vazquez, Appl. Clay Sci. 41 (2008) 24-36.

[6] N. Sarier, E. Onder, S. Ersoy, Coll. Surf. A 371 (2010) 40-49.

[7] M. Motak, Catal. Today 137 (2008) 247-252.

[8] P. Lertsutthiwong, N.C. How, S. Chandrkrachang, W.F. Stevens, J. Met. Mater Miner. 12 (2002) 11-18.

[9] M.N.R. Kumar, React. Funct. Polym. 46 (2000) 1-27.

[10] C. Pillai, W. Paul, C.P. Sharma, Prog. Polym. Sci. 34 (2009) 641-678.

[11] S.F. Wang, L. Shen, Y.J. Tong, L. Chen, I.Y. Phang, P.Q. Lim, T.X. Liu, Polym. Degrad. Stab. 90 (2005) 123-131.

[12] S. Wang, L. Chen, Y. Tong, J. Polym. Sci. A: Polym. Chem. 44 (2006) 686-696.

[13] M. Darder, M. Colilla, E. Ruiz-Hitzky, Appl. Clay Sci. 28 (2005) 199-208.

[14] H. Wang, H. Tang, Z. Liu, X. Zhang, Z. Hao, J. Environ. Sci. (China) 26 (2014) 1879-1884.

[15] L. Wang, A. Wang, J. Hazard. Mater. 147 (2007) 979-985.

[16] S.-h. Hsu, M.-C. Wang, J.-J. Lin, Appl. Clay Sci. 56 (2012) 53-62.

[17] L. Boudriche, A. Chamayou, R. Calvet, B. Hamdi, H. Balard, Powder Technol. 254 (2014) 352-363.

[18] C. Bilgiç, D. Topaloğlu Yazıcı, N. Karakehya, H. Çetinkaya, A. Singh, M.M. Chehimi, Int. J. Adhes. Adhes. 50 (2014) 204-210.

[19] A. Tamayo, J. Kyziol-Komosinska, M.J. Sánchez, P. Calejas, J. Rubio, M.F. Barba, J. Eur. Ceram. Soc. 32 (2012) 2831-2841.

[20] B. Shi, S. Zhao, L. Jia, L. Wang, Carbohydr. Polym. 67 (2007) 398-402.

[21] N. Karakehya, C. Bilgiç, Int. J. Adhes. Adhes. 51 (2014) 140-147.

[22] K. Boukerma, J.-Y. Piquemal, M.M. Chehimi, M. Mravčáková, M. Omastová, P. Beaunier, Polymer 47 (2006) 569-576.

$23]$ X. Ma, X. Qu, Q. Zhang, F. Chen, Polymer 49 (2008) 3590-3600.

[24] G.M. Dorris, D.G. Gray, J. Colloid Interface Sci. 77 (1980) 353-362.

[25] H. Balard, E. Brendlé, E. Papirer, Acid-Base Interact. Relevance Adhes. Sci. Technol. 2 (2000) 299-316.

[26] J. Conder, C. Young, Willey, NY (1979).

[27] H. Balard, D. Maafa, A. Santini, J. Donnet, J. Chromatogr. A 1198 (2008) $173-180$.

[28] W. Rudziński, J. Jagiełło, Y. Grillet, J. Colloid Interface Sci. 87 (1982) 478-491.

[29] H. Balard, Langmuir 13 (1997) 1260-1269.

[30] F.A. Tirkistani, Polym. Degrad. Stab. 61 (1998) 161-164.

[31] X. Qu, A. Wirsen, A.-C. Albertsson, Polymer 41 (2000) 4841-4847.

[32] A. Leszczynska, K. Pielichowski, J. Therm. Anal. Calorim. 93 (2008) 677-687.

[33] P. Monvisade, P. Siriphannon, Appl. Clay Sci. 42 (2009) 427-431.

[34] M. Pan, X. Shi, X. Li, H. Hu, L. Zhang, J. Appl. Polym. Sci. 94 (2004) 277-286.

[35] M. Gironès, L. Bolhuis-Versteeg, R. Lammertink, M. Wessling, J. Colloid Interface Sci. 299 (2006) 831-840.

[36] S. Yang, N. Okada, M. Nagatsu, J. Hazard. Mater. 301 (2016) 8-16.

[37] T.J. Bandosz, K. Putyera, J. Jagiełło, J.A. Schwarz, Microporous Mater. 1 (1993) 73-79.

[38] M. Mravčáková, K. Boukerma, M. Omastová, M.M. Chehimi, Mater. Sci. Eng. C 26 (2006) 306-313.

[39] M.-P. Comard, R. Calvet, J.A. Dodds, H. Balard, J. Chromatogr. A 969 (2002) 93-96.

[40] B. Strzemiecka, M. Kasperkowiak, M. Łożyński, D. Paukszta, A. Voelkel, Microporous Mesoporous Mater. 161 (2012) 106-114. 